\title{
Impact of Business Incubators' Facilities on Entrepreneurial Ecosystem Creation: A Case of Business Incubator in Jordan
}

\author{
Ibrahim Adnan Al-Shamaileh ${ }^{1}$, Ezgi Yildirim Saatci ${ }^{1} \&$ Patrick Ekpenyong Eyamba ${ }^{1}$ \\ ${ }^{1}$ Business Faculty, Istanbul Okan University, Istanbul, Turkey \\ Correspondence: Ibrahim Adnan Alshamaileh, Faculty of Business, Istanbul Okan University, Istanbul, Turkey. \\ E-mail: shamaileh_jor@yahoo.com
}

Received: February 24, 2020

Accepted: May 16, 2020 Online Published: May 26, 2020

doi:10.5539/jms.v10n1p189

URL: https://doi.org/10.5539/jms.v10n1p189

\begin{abstract}
This study aims at reflecting the impact of business incubator facilities on the creation of an entrepreneurial ecosystem with a focus on the major business incubator in Jordan - King Hussein Business Park - as it expanded new land within a critical large expansion plan through five phases with a full occupancy rate. This example shows more details on how to further develop planned entrepreneurial activities to attract new clients to occupy expanded spaces by focusing on creating a supportive ecosystem for entrepreneurship. This study was conducted on the top and middle management of the companies in the business hub KHBP, the sample consisted of (300) directors. In this context, infrastructure, governmental tax benefits, and services provided are hypothesized to have an effect on the entrepreneurial ecosystem in addition to that the outcomes of this study disclose a favorable influence for the facilities on creation supportive entrepreneurial climate. Infrastructure, Governmental law benefits, and services are found to be significant in the creation of a charming business climate for entrepreneurs. The study's findings demonstrate that countries with scant exchequers face a lot of troubles in creating an attractive and supportive ecosystem for entrepreneurial activities, and they have to get better their business environment for entrepreneurship development. Governmental policies and reforms also play a vital role in making the projects and businesses much simply.
\end{abstract}

Keywords: entrepreneurship, infrastructure development, ecosystem creation, governmental law benefits, services

\section{Introduction}

Competition in how to create an attractive entrepreneurial environment in order to obtain economic evolution has been growing at domestic and international spheres, especially for developing nations. Increasing interest in the topic of entrepreneurship and SME development in recent years has contributed to the process of economic development and the development of the competitive environment of local and international organizations due to supporting the national economy. The concept of Entrepreneurship comes from Joseph Schumpeter and some Austrian economists such as Ludwig von Mises and von Hayek (Apostol \& Jatuliavičiené, 2013).

The vital part which was made by the entrepreneurs of developed countries in creating an attractive and supportive climate which led to attain the economic evolution has driven the people of developing countries to care about the value of entrepreneurial activities and has encouraged them to be a crucial part of the entrepreneurial society (Loss \& Bascunan, 2011, p. 21).

The perspectives of developing entrepreneurship depend on robust infrastructure which needs to be attractive for entrepreneurs to develop their entrepreneurial projects in order to achieve their economic goal and stability. Also, there are other factors leading to attain the required entrepreneurial objectives and to have a sustainable competitive advantage (Morozova, Popkova, \& Litvinova, 2019).

Entrepreneurs are substantial inputs in the development process of countries. Their skills and efficiency play a critical part in making the different rates of economic evolution. On the other hand, this different rate cannot be attained without focusing on other parts such as; the social, political, and economic conditions. Developing infrastructure, establishing supportive facilities, and governmental reforms help entrepreneurs in achieving the required outputs in the economic process (Arora, 2012).

In order to create an attractive business climate for investors and entrepreneurs, governmental reforms and 
policies are necessary to solve the problems which hinder entrepreneurial growth. Investment law benefits and governmental policies have an impact on the climate of SME's activities. The economic stability and business reforms in Africa are totally different compared with developing countries (Munemo, 2012). Governmental, cultural, and social forces play a big role in creating a supportive entrepreneurial climate that contributes to economic growth in several nations in the world. Entrepreneurial activities in countries with a healthy economic environment and climates are better than other countries. Tax incentives and exemptions are the best inputs in this crucial difference (Marples, 2007).

Jordan has been interested in this issue from an early date, and its story tells the history of microfinance in Jordan. Recently, it started with the Jordan River Community Empowerment Program with the aim of enhancing the capacity of disadvantaged communities by providing economic opportunities and improving their level of living. Jordan has one of the farthest open economies in the Middle East, which was derived from governmental reforms and market-oriented reforms in the few past years. Jordan provides a unique example of the Arab entrepreneurship movement, not only in promising entrepreneurial models launched by Jordanian youth but also in developing the social mechanisms that embrace these projects and make them see the light, whether through private business incubators or government institutions. This is the summary of interactions between governmental agencies, educational institutions, and private enterprises (Schiff, Schmidt, \& Troncoso, 2015).

The largest business campus in Jordan is King Hussein Business Park (KHBP). They have succeeded in attracting well-known international, regional, and local companies and startups. They enhanced their position as Jordan's active business hub and an incubator of innovation and creativity because they have a sturdy infrastructure, integral services, and government benefits which created a supportive and attractive business climate. (Retrieved from http://www.businesspark-jo.com/en-us/) They have a well-known supportive initiative for entrepreneurship called (Grow).

Jordan believes that "The maturity of the entrepreneurial environment is not measured by the number of startups, but by the transformation of entrepreneurship into an integrated system in which everyone collaborates". (Retrieved from http://www.businesspark-jo.com/StartupsOfficeSpaceGrow?menu=4108). Nowadays, Jordan is a supportive climate that encourages creativity, education, innovation, fabrication labs, and entrepreneurial projects.

The main objectives of this study are to assess the impact of services, infrastructure, and governmental law benefits on creating a supportive and attractive environmental ecosystem for entrepreneurs. This study will contribute to clarifying the impact of the business incubator's facilities on improving and developing the entrepreneurial climate effectively, especially as the quality of the entrepreneurial climate helps in attracting investments and developing the economic wheel of the country.

The importance of this study is that it talks about a very important topic in business administration, which is creating an entrepreneurial ecosystem and how it can be affected by the provided facilities by the business incubators. This topic leads to full knowledge about the impact of services, infrastructure, and government law benefits, whether positive or negative, on the entrepreneurial ecosystem creation, increasing the opportunity for more new investments, increasing competition, and enhancing economic stability of the industrial and services sector. Theoretically, this study seeks to explore the dimensions and factors that affect entrepreneurship. It also seeks to provide a humble effort related to business incubators, which can get the interests of researchers and be a starting point for new research in the field of study. Practically, this study is expected to provide findings and recommendations for many sectors such as the industrial sector, the services sector, tourism, the media, education and healthcare sectors, international organizations, and NGOs with regard to the entrepreneurial ecosystem.

\section{Literature Review}

Developing entrepreneurial activities and having an attractive climate for SME's are crucial interest to make the economic growth wheel moves faster all around the world. In West Bengal, (SMEs) Small and medium enterprises have a dynamic impact within the Indian market because they have the utmost resources, complementary services, innovation, fostering inter-sectoral relationships, and developing entrepreneurial skills. Also, there are many economic factors that have a good contribution to economic growth in West Bengal such as; governmental reforms, tax incentives, and financial facilities. But still, now there are many obstacles faced by these enterprises such as; inadequate infrastructure facilities, and lack of access to the global market (Ganguly, 2013).

In China, the private sector has faced many problems at the first because of lack of interaction between the government and private sector which prevents achieving the required development, also lack of continues 
governmental support and reforms drove the private sector to get stuck in a lot of problems related to infrastructure which also prevents to enable the private sector to grow and promote enterprises (Atherton \& Smallbone, 2010).

Serbia started the transformation process in the year 2000 because it faced many troubles in achieving sustainable development of the entrepreneurial sector because of the lack of a number of small and medium-sized companies (SMEs), as the Serbian economy was suffering a lot from the problem of economic growth in the period 2009-2014, in addition to, the ecosystem and the entrepreneurial climate is deteriorating significantly due to the lack of government support for small and medium-sized companies, in (2015 and 2016) the Serbian government managed to control the budget deficit after directing the government support and the governmental laws benefit towards these entrepreneurial companies and a lot of government reforms were undertaken in this period in which the Serbian government was able to achieve significant success in creating a supportive entrepreneurial ecosystem in order to improve economic development (Hadzic \& Pavlovic, 2019).

The Turkish study (Uslu, Hancıoğlu, \& Demir, 2015) indicated that tax incentives and governmental support in addition to the various services provided by the Turkish government to entrepreneurs and owners of small and medium-sized companies (SMEs) contribute effectively to creating an entrepreneurial ecosystem that helps to develop entrepreneurial businesses and motivates entrepreneurs to develop their businesses in addition to improve the sustainable development. Green entrepreneurship is mainly based on the environment that supports these kinds of projects. There is also a great harmony between different NGOs and governmental organizations in Turkey in terms of providing tax incentives and integrated services in order to achieve regional development.

Bangladesh showed other examples of the influence of the financial laws, governmental services, political stability, education, and infrastructure facilities on the development of SMEs and the creation of a healthy climate for entrepreneurs. Chowdhury (2007) has pointed out that the positive business climate with complimentary services has a competitive advantage in attracting investors and promoting skilled entrepreneurs then developing the SMEs in Bangladesh.

The study of Robertson (2006) aims to assess the market situation based on the ability of policymakers to develop different policies and evaluate them based on ecosystem services and facilities that help in creating an ecosystem that aids to solve problems related to assessing the success of ecosystem services markets in order to reduce the challenges facing markets and to obtain an ecological environment leading to the success of industrial and service markets and entrepreneurship.

The study of Smirnov, Richter, Ekaterina and Galina (2020, March) states that Russia has faced many problems related to economic development. Russia has done a lot of studies regarding how to create an entrepreneurial ecosystem that supports entrepreneurial activities in the Russian market, but it has discovered that it did not pay close attention to economic aspects and state policy. Therefore, Russia has begun to work well in directing the governmental support toward economic activities in the markets, so it established a supportive project for entrepreneurs under the name (Supporting National Projects) and launched several support programs that affect the regional level, it also created information technology platforms such as (My business) \& (Business Navigator) with aiming at directing the governmental support toward entrepreneurs and thus made Russia capable to create a charming entrepreneurial ecosystem in its markets and improve the sustainable economic development.

Business incubators aim at providing entrepreneurs and SMEs managers with a supportive climate provided with robust infrastructure so they can establish and grow their enterprises. Also, they aim at assisting and empowering entrepreneurs by providing them with business support, Infrastructure means the physical tangible services while business support means intangible services. Business incubators in Norway are caring about the both tangible and intangible support presented to entrepreneurs to help and empower them to achieve their growth and development in a healthy business environment (Robinson \& Stubberud, 2014).

It is very hard to develop the entrepreneurial environment if there are not enough financial and economic resources. Entrepreneurs need to get support due to establish and progress their enterprises, the government must focus on providing them with the required facilities and legal issues such as investment law benefits, also decreasing the obstacles which restrain creating a good business climate and hinder their success and development (Bilas, France, \& Cenan, 2011).

Synergy is the key factor that increases the economic stability for SMEs because it is the required interaction between government and private sector, this synergy has many types which foster the development of entrepreneurial activities such as; social synergy, investment synergy, logistic synergy, synergy of use of resources, innovative synergy, and market synergy. Governmental facilities lead to develop the infrastructure for all entrepreneurs then help them to develop their projects and sustain their success (Borisovich, Sergeevna, 
Adgamovna, \& Gumerovna, 2017).

Technological entrepreneurial ecosystem start-ups are playing a vital role in catching the concern of policymakers and attracting foreign companies globally. Increased universal confession has been received by Indian Bangalore as a tech incubator hub; It is the residence for the greatest number of tech incubators locally and globally. This achievement led to the creation of a supportive entrepreneurial environment. The support introduced by the Indian government and the evolution of a unique entrepreneurial ecosystem is the important factor that has a good contribution to this recognition of Bangalore, which supports and promotes tech start-ups (Bala, 2017).

The study (Mateos \& Amorós, 2019) compared regional economic policies in startups that were created with the aim of improving local economic development. This study distributed the questionnaire to a sample consisting of (675) of national experts in Mexico. This study used several statistics in order to compare the differences between these experts in Mexico. The results indicated that the experts in central regions in terms of government support, government reforms, research and development, and enough provided services are in a much better position than experts located in decentralized areas and do not have the required government support and financial facilities in order to create an ecosystem that supports entrepreneurs to improve entrepreneurship and develop the emerging economic activities (start-ups).

The Indian study (Kumar \& Das, 2019) on how to assess the role of infrastructure in the success of emerging economies and entrepreneurial businesses relied on several factors which are: methodology, design, and approach. This study was conducted on postgraduate students at the Indian Institute of Management, this sample consisted of (265) students. This study indicated that there is a large role of infrastructure in the intention of entrepreneurs in taking the decision to carry out their entrepreneurial projects in light of the existence of a robust infrastructure that helps to create an effective entrepreneurial ecosystem. This study demonstrated that infrastructure and the availability of the necessary resources affect on the success of emerging companies. Stakeholders and policymakers should heavily focus on building an entrepreneurial ecosystem that promotes sufficient institutional infrastructure to foster entrepreneurship.

The study of Xu and Dobson (2019) indicated that the most important challenges facing building a supportive ecosystem of entrepreneurship are the lack of resources, financial issues related to financing, infrastructure, supportive services, governmental policies in the economic markets, and social culture. This study contributed to developing the comprehensive concept of building an appropriate ecosystem for entrepreneurs in the peripheral areas and elaborated good practices for policymakers in order to foster and improve the sustainable economic growth.

Counting on the helpful and supportive results in the previously existing literature in addition to the theoretical background for many researchers, we suggest the following hypotheses:

H1: Business incubator's facilities have a statistically significant positive impact on Entrepreneurship.

H1.1: Infrastructure of the Incubation Center has a statistically significant positive impact on Entrepreneurial Ecosystem Creation.

H1.2: Governmental law benefits have a statistically significant positive impact on Entrepreneurial Ecosystem Creation.

H1.3: Services provided by the Incubation center have a statistically significant positive impact on Entrepreneurial Ecosystem Creation.

\section{Methodology}

The descriptive-analytical method was used by the researcher to assort the data then analyze it. The different views were recorded during the study then were given and described through many tables and graphs. The researcher used this process to get enough measurements (Robinson \& Stubberud, 2014).

A questionnaire was made by the researcher in order to cover all the study's independent and dependent variables. The questionnaire was formulated then handed out to the top and middle management in the sample unit in order to raise the reliability of the collected data. The researched used Nine items to measure the impact of infrastructure on Entrepreneurship (Ganguly, 2013), utilized eight items to estimate the impact of governmental laws benefits on entrepreneurship creation (Arora, 2012), and used six items in order to estimate the effect of incubator's facilities on Entrepreneurship (Munemo, 2012; Robinson \& Stubberud, 2014). Study variables were measured counting on the including criteria in former studies. A five-point Likert scale was utilized by the researcher to attain the study's purposes (Hair, Black, Babin, \& Anderson, 2010). 
Whole companies within King Hussein Business Park were included in the distribution of questionnaires and data collection. The researcher distributed the questionnaire in order to collect the data. The study population contained 150 well-known firms. Seven trade sections (international organizations, information \& communications technology, healthcare, education, start-ups, media, and NGOs) were taken into consideration by the researchers. The researchers distributed questionnaires; 300 questionnaires were turned back after being filled.

The face validity was tested to cognize the questions linked together and guarantee the matchmaking of the responses. It was presented to a set of long-practiced professionals and tighteners included many educational professors to assess its validity as an instrument in order to gather data. Cronbach's alpha coefficient was utilized by the researcher to guarantee that the necessary data was gathered by a reliable instrument. Cronbach's alpha coefficient's results are higher than $70 \%$ for whole study variables: infrastructure, 0.780 ; governmental laws benefits, 0.877; services, 0.797; and, creation of an entrepreneurial ecosystem, 0.707. These outcomes are agreeable depending on Hair, Anderson, Tatham and Black (2010), also, they are pointed out in the book Research Methods for Business-Uma Sekaran on page 311. There is an internal consistency in the whole items mentioned in the questionnaire, also, there is a reliability in the outcomes.

\section{Respondents Profile}

300 directors have done the questionnaire model. The respondents' percentage was as follows; the percentage of males was $47.2 \%$, and the percentage of females was $52.8 \%$. The managers from 30 to 35 years old were graded first with proportion $27.8 \%$. But the managers from 20 to 25 years old were the lowest category with proportion $6 \%$. Regarding the career level, operations officers were classified as the highest category of respondents with proportion $(38.2 \%)$ the general managers were graded second with percentage $(31.8 \%)$, but the operations managers were the lowest category with percentage $30 \%$. Most directors had sufficient experiments and knowledge and they were competent for their workplace and position. Regarding academic qualification, bachelor's degree was ranked first-class with the highest percentage $47.7 \%$, master's degree was graded second category with proportion $31.9 \%$, diploma degree was graded third category with percentage $15.8 \%$, the fourth one was Ph.D. with proportion $3.7 \%$, but the high school diploma was the lowest category with percentage $0.9 \%$. The utmost of the respondents was educated, qualified, and skilled. They also had sufficient workable know-how, pointing out that the experienced managers had filled the study questionnaire; the utmost of respondents had 5 to 10 years of experience with proportion $42.0 \%$. 65 respondents were less than 5 years with proportion $21.7 \%$, the lowest class was the managers more than 15 years with proportion $16.3 \%$. Regarding the longitude of their projects, the utmost of the projects was from 1 to 3 years old with proportion $30.3 \%$, the projects from 3 to 5 years old were ranked second with proportion $28.3 \%$, the projects from 5 to 8 years old were classified third with proportion $23.3 \%$, the last one is projects more than 8 years old with proportion $18.1 \%$.

The study included managers at the top and middle levels in King Hussein Business Park such as General Managers, Chief Executive Officers, Financial Officers, Human Resources Managers, Procurement Managers, and Marketing Managers. The study was exclusive to International Organizations, ICT, Education Sectors, Media, Healthcare, and NGO companies in King Hussein Business Park.

\section{Data Analysis Results}

Accordingly; there was moderation in the responses. The distributed variables didn't contain dispersion. There was no violation in the linearity assumption because there was no link between the expected and residual values. Test of Durbin-Watson was 1.978, which is between (1.5 and 2.5) regarding (Hair, Anderson, Tatham, \& Black, 1995). R Square test was (0.248), which indicates that $24.8 \%$ of the variation in the dependent variable is the responsibility of the study independent variables and $75.2 \%$ of the variation are linked to other variables. The relationship was mostly moderate between independent variables and dependent variables due to (R-value equals 0.498). The value of adjusted R Square equals 0.245 .

Later, several Hierarchical Regression Models were conducted by the researcher in order to exam the impact of the business incubator's facilities on creating an entrepreneurial ecosystem as shown in Table 1.

Table 1. Coefficients ${ }^{\text {a }}$ - the main hypothesis

\begin{tabular}{|c|c|c|c|c|c|c|c|c|}
\hline \multirow{2}{*}{\multicolumn{2}{|c|}{ Model }} & \multicolumn{2}{|c|}{ Unstandardized Coefficients } & \multirow{2}{*}{$\begin{array}{l}\text { Standardized Coefficients } \\
\text { Beta }\end{array}$} & \multirow[t]{2}{*}{$\mathrm{T}$} & \multirow[t]{2}{*}{ Signi. } & \multicolumn{2}{|c|}{ Collinearity Statistic } \\
\hline & & $\mathrm{B}$ & Std. Error & & & & Tolerance & VIF \\
\hline \multirow[t]{2}{*}{1} & (Constant) & 1.005 & .089 & & 11.312 & .000 & & \\
\hline & Average IVs & .494 & .050 & .498 & 9.908 & .000 & 1.000 & 1.000 \\
\hline
\end{tabular}

Note. a. Dependent Variable: Average DV “Entrepreneurship”. 
Table 1 displays the strength of the impact of the average facilities provided by the business incubation center on average Entrepreneurship $(B e t a=0.498)$. T-value marks whether the sample mean is different statistically from a population mean (T-test $=9.908)$, the significance level was less than 0.05 . As a result, the hypothesis $\mathbf{H 1}$ has been accepted. H1 states that business incubator's facilities have a statistically significant positive impact on Entrepreneurship.

Table 2. Coefficients ${ }^{\text {a }}$ - the sub hypotheses

\begin{tabular}{|c|c|c|c|c|c|c|c|}
\hline \multirow[t]{2}{*}{ Model } & \multicolumn{2}{|c|}{ Unstandardized Coefficients } & \multirow{2}{*}{$\begin{array}{l}\text { Standardized Coefficients } \\
\text { Beta }\end{array}$} & \multirow[t]{2}{*}{$\mathrm{T}$} & \multirow[t]{2}{*}{ Sig. } & \multicolumn{2}{|c|}{ Collinearity Statistics } \\
\hline & $\mathrm{B}$ & Std. Error & & & & Tolerance & VIF \\
\hline (Constant) & 1.205 & .119 & & 10.163 & .000 & & \\
\hline Average IVs & .373 & .067 & .309 & 5.599 & .000 & 1.000 & 1.000 \\
\hline
\end{tabular}

Note. a. Dependent Variable: Entrepreneurial Ecosystem Creation.

Table 2 displays the strength of the impact of average independent variables on entrepreneurial ecosystem creation $(B e t a=0.309)$. T-value was 5.599, in addition to the significance level was less than 0.05 . As a result, the hypothesis H1.1 has been accepted. H1.1 states that Infrastructure of the Incubation Center has a statistically significant positive impact on Entrepreneurial Ecosystem Creation. the hypothesis H1.2 has been accepted. H1.2 states that Governmental law benefits have a statistically significant positive impact on Entrepreneurial Ecosystem Creation. the hypothesis H1.3 has been accepted. H1.3 states that Services provided by the Incubation center have a statistically significant positive impact on Entrepreneurial Ecosystem Creation.

Table 3. Multiple regression - the sub hypotheses

\begin{tabular}{|c|c|c|c|c|c|c|c|}
\hline \multirow[t]{2}{*}{ Coefficients ${ }^{\mathrm{a}}$ Model } & \multicolumn{2}{|c|}{ Unstandardized Coefficients } & \multirow{2}{*}{$\begin{array}{l}\text { Standardized Coefficients } \\
\text { Beta }\end{array}$} & \multirow[t]{2}{*}{$\mathrm{T}$} & \multirow[t]{2}{*}{ Sig. } & \multicolumn{2}{|c|}{ Collinearity Statistics } \\
\hline & $\mathrm{B}$ & Std. Error & & & & Tolerance & VIF \\
\hline (Constant) & 2.082 & .219 & & 9.513 & .000 & & \\
\hline Infrastructure & .095 & .046 & .111 & 2.069 & .039 & .863 & 1.158 \\
\hline Govern law benefits & .118 & .028 & .215 & 4.141 & .000 & .917 & 1.091 \\
\hline Services & .266 & .040 & .363 & 6.727 & .000 & .851 & 1.176 \\
\hline
\end{tabular}

Note. a. Dependent Variable: Average DV "Entrepreneurship".

Table 3 displays the strength of the impact of the business incubator's facilities on average entrepreneurship. The results point out a positive direct impact of the IVs on average DV; the strength of the impact of Infrastructure (IV1) on average entrepreneurship (Beta $=0.111$ ), the strength of the impact of Governmental Law Benefits (IV2) on average entrepreneurship (Beta $=0.215$ ), and the strength of the impact of Services (IV3) on average entrepreneurship (Beta $=0.363$ ). T-values were as follows: T-test of IV1 $=2.069$, T-test of IV2 $=4.141$, and T-test of IV3 $=6.727$. The significance level of all IVs is less than 0.05. As a result, all Sub Hypotheses (H1, H1.1, H1.2, H1.3) have been accepted.

\section{Discussion and Conclusion}

This study pointed out that most of the respondents are well-educated which shows that adequate awareness plays a great part in an entrepreneurial ecosystem creation that helps to promote entrepreneurial activities (Chowdhury, 2007). Governmental reforms have a dynamic impact on creating an attractive business environment for entrepreneurs and attaining domestic economical evolution and development (Schiff et al., 2015). Services and supply assist extremely in obtaining a supportive business climate for entrepreneurs. These conclusions are in a parallel line with that of prior study (Borisovich et al., 2017). There is a great contribution by business incubators in the development of entrepreneurship, innovation, and creating a supportive business climate that helps to attract entrepreneurs through providing administrative and technical support, services, financing, and incubating creative ideas and patents. This is what this study attained in addition to other previous studies (Apostol \& Jatuliavičienè, 2013; Morozova et al., 2019). Infrastructure facilities have an impact on entrepreneurship (Munemo, 2012). Other factors that are also shown in the study have an effective impact on creating an entrepreneurial environment such as: Strategic location, access to international markets, and quality building development (Ganguly, 2013).

This study attained sundry outcomes. The major one is the robust impact of infrastructure, governmental law benefits, and services on creating an entrepreneurial ecosystem and an attractive business climate for start-ups. 
states with rare resources have to progress and enhance their business environment to develop entrepreneurship. Plenty of problems and challenges disturb of entrepreneurship development, like the pluralism of government references, contract affairs, and legal complications. Governmental reforms and co-operation are one of the best solutions for the previous challenges.

The influence of government policies on phases of entrepreneurship particularly for specific business and economic sectors needs great attention, so policymakers seeking to effectively encourage entrepreneurship may target on boosting entrepreneurial activity in such will promote the revenue base and development of any economy. Implementing new advanced technology and management system for these businesses to spring will encourage the establishment of business climate and investors globally. The following major components of this approach can be offered to enhance the existing support for regulatory compliance in improving the tax system for financial credit mechanisms.

The researcher introduces helpful and useful recommendations for creating a supportive entrepreneurial ecosystem in Jordan, Also, these recommendations are very beneficial for upcoming future researches. Jordan wants to concentrate heavily on improving integrated strategic policies and plans to allow the government to best invest in human resources and to achieve development in addition to enhance its impact in creating the best-required climate for entrepreneurship.

Focus on providing all cities in Jordan with required services \& training and facilitating the procedures of entrepreneurial activities to give all people the same opportunity to get a supportive environment for entrepreneurial projects and thus achieving economic development. The significance of cooperation between educational institutions and all sectors associated with the environment of entrepreneurship to meet the demands of the business markets in Jordan. Eventually, depending on specialized R\&D Centers in order to evaluate the entrepreneurial development programs, the sustainability of this development activity should be given high priority and effort in encouraging investors.

\section{References}

Apostol, T., \& Jatuliavičienè, G. (2013). Evaluation of Entrepreneurship Development Possibilities by Example of Small and Medium Enterprises in the Republic of Moldova. Regional Formation \& Development Studies, 11(3), 24-38. https://doi.org/10.15181/rfds.v11i3.607

Arora, V. K. (2012). Essentials for Entrepreneurship Development. Globsyn Management Journal, 6(1/2), 51-59.

Atherton, A., \& Smallbone, D. (2010). State promotion of SME development at the local level in China: An examination of two cases. Journal of Chinese Entrepreneurship, 2(3), 225-241. https://doi.org/10.1108/17561391011078721

Bala, S. M. (2017). How did Bangalore emerge as a global hub of tech start-ups in India? entrepreneurial ecosystem-evolution, structure and role. Journal of Developmental Entrepreneurship, 22(01), 1750006. https://doi.org/10.1142/S1084946717500066

Bilas, V., France, S., \& Ćenan, D. (2011). The Role of the Government in the Entrepreneurship Promotion and Development of the Institutional Support to Exports. University of Zagreb, Faculty of Economics and Business J.F. Kennedy sq. 6, 10000 Zagreb, Croatia. 89602709.

Borisovich, P. R., Sergeevna, S. N., Adgamovna, S. V., \& Gumerovna, K. N. (2017). Analysis of Entrepreneurship Attempts and Infrastructure. Journal of Economic \& Management Perspectives, 11(3), $1647-1655$.

Chowdhury, M. S. (2007). Overcoming entrepreneurship development constraints: the case of Bangladesh. Journal of Enterprising Communities: People and Places in the Global Economy, 1(3), 240-251. https://doi.org/10.1108/17506200710779549

Ganguly, S. (2013). Micro, small and medium enterprises in West Bengal: An evaluation. CLEAR International Journal of Research in Commerce \& Management, 4(10).

Hadzic, M., \& Pavlovic, P. (2019). Rethinking Strategy for SMEE Support in the Light of the Entrepreneurial Ecosystem. Emerging Science Journal, 3(6), 389-394. https://doi.org/10.28991/esj-2019-01201

Hair, J., Anderson, R., Tatham, R., \& Black, W. (1995). Multivariate Data Analysis with Reading (4th ed.). Upper Saddle River, N.J.: Prentice-Hall International. Includes bibliographical references and index. c1995. 0139305874 (international ed.) 0138948585. 
Hair, J. F., Black, W. C., Babin, B. J., \& Anderson, R. E. (2010). Multivariate Data Analysis (7th ed.). Prentice Hall, Upper Saddle River, New Jersey.

Kumar, S., \& Das, S. (2019). An Extended Model of Theory of Planned Behaviour. Journal of Entrepreneurship in Emerging Economies, 11(3), 369-391. https://doi.org/10.1108/JEEE-09-2018-0089

Loss, M., \& Bascunan, F. L. (2011). Entrepreneurship Development (1st ed.). Global Vision Publishing House.

Marples, D. (2007). State and Local Tax Policy: Evidence of its Effect on Entrepreneurship (Vol. 99, pp. 225-230). In Proceedings. Annual Conference on Taxation and Minutes of the Annual Meeting of the National Tax Association. National Tax Association.

Mateos, A. O. V., \& Amorós, J. E. (2019). Regional entrepreneurial ecosystems in Mexico: a comparative analysis. Journal of Entrepreneurship in Emerging Economies, 11(4), 576-597. https://doi.org/10.1108/JEEE-02-2019-0024

Morozova, I. A., Popkova, E. G., \& Litvinova, T. N. (2019). Sustainable development of global entrepreneurship: infrastructure and perspectives. International Entrepreneurship and Management Journal, 15(2), 589-597. https://doi.org/10.1007/s11365-018-0522-7

Munemo, J. (2012). Entrepreneurship in Developing Countries: is Africa Different? Journal of Developmental Entrepreneurship, 17(1), 1-12. https://doi.org/10.1142/S1084946712500045

Robertson, M. M. (2006). Emerging ecosystem service markets: trends in a decade of entrepreneurial wetland banking. Frontiers in Ecology and the Environment, 4(6), 297-302. https://doi.org/10.1890/1540-9295(2006)4[297:EESMTI]2.0.CO;2

Robinson, S., \& Stubberud, H. A. (2014). Business incubators: what services do business owners really use? International Journal of Entrepreneurship, 18, 29.

Schiff, A., Schmidt, N., \& Troncoso, J. (2015, May). Entrepreneurship Environment Assessment in Jordan. Silatech Research and Policy Report. University of Minnesota, Humphrey School of Public Affairs.

Smirnov, S., Richter, K., Ekaterina, M., \& Galina, I. (2020, March). On the Way to the Mass Entrepreneurship in Russia: Currents State and Trends (pp. 142-146). In 2020 6th International Conference on Information Management (ICIM). IEEE. https://doi.org/10.1109/ICIM49319.2020.244687

Uslu, Y. D., Hancıoğlu, Y., \& Demir, E. (2015). Applicability to green entrepreneurship in Turkey: A situation analysis. Procedia-Social and Behavioral Sciences, 195, 1238-1245. https://doi.org/10.1016/j.sbspro.2015.06.266

Xu, Z., \& Dobson, S. (2019). Challenges of building entrepreneurial ecosystems in peripheral places. Journal of Entrepreneurship and Public Policy, 8(3), 408-430. https://doi.org/10.1108/JEPP-03-2019-0023

\section{Copyrights}

Copyright for this article is retained by the author, with first publication rights granted to the journal.

This is an open-access article distributed under the terms and conditions of the Creative Commons Attribution license (http://creativecommons.org/licenses/by/4.0/). 